\title{
EDITORIAL
}

\section{Tardive dyskinesia: natural history studies assist the pursuit of preventive therapies ${ }^{1}$}

Contemporary thinking about tardive dyskinesia is undergoing a quiet revolution. In the fourth decade following the introduction of neuroleptic medications for the treatment of schizophrenia, tardive dyskinesia research has moved from debates over its very existence to careful, scholarly sub-typing of clinical variants. Investigators are also beginning to elucidate the epidemiology and natural history of tardive dyskinesia as a proper disease. These present-day research endeavours are setting the stage for what we all hope will be the next era of research in this field: namely, treatment and prevention.

If the pre-eminent challenge in the field of tardive dyskinesia research is to discover an antipsychotic drug which does not cause tardive dyskinesia, why are investigators interested in the natural history of tardive dyskinesia? One of the major reasons is the need for a strategy whereby the presence or absence of acute drug effects could be predictive of chronic drug effects (Stahl, 1985). That is, can we be confident that a new antipsychotic drug without the acute side-effects of akathisia or Parkinsonism will also not cause the chronic side-effect of tardive dyskinesia? Only upon completion of careful prospective studies of the natural history of acute neuroleptic side-effects merging with chronic neuroleptic side-effects, superimposed upon the natural history of schizophrenia, will we be able to generate with any confidence a clinical research strategy for antipsychotic drugs which do not produce tardive dyskinesia.

\section{TARDIVE DYSKINESIA SUB-TYPES AND VARIANTS}

Tardive dyskinesia can have many definitions and, indeed, many clinical manifestations (see Table 1). Early investigators needed to define tardive dyskinesia as an iatrogenic disease rather than a spontaneous movement disorder in psychotic patients. Originally, tardive dyskinesia was described as oro-buccal-lingual-masticatory dyskinesias (DeVeaugh-Geiss, 1982). However, numerous investigators later documented that the clinical consequences of chronic neuroleptic treatment can be quite varied (see Table 1). In fact, at least seven variants of tardive dyskinesia are described and include not only the classical movement disorder of the oro-buccal-lingual dyskinetic type, but also limb dyskinesias, a Tourette-like syndrome, dystonia and akathisia, as well as mental symptoms such as supersensitivity psychosis and dysmentia (for sources, see Table 1). Despite nosological debates on each variant in Table 1 , it is nevertheless clear that neuroleptic treatment can produce manifestations in patients undergoing chronic therapy which are quite different from oro-buccal-lingualmasticatory dyskinesias.

\section{NATURAL HISTORY}

Delineation of tardive dyskinesia variants demonstrates that neuroleptics can have multiple clinical consequences. However, these variants have produced a great deal of confusion, since the study of the natural history of how these variants evolve and how they merge with one another has been largely neglected. Current research is focusing on just these issues. The state of the art today is the study of the process whereby acute neuroleptic side-effects merge with chronic neuroleptic side-effects (Stahl, 1985). Barnes \& Braude (1985) have proposed, for example, a natural history scenario for the clinical consequences of long-term neuroleptic treatment. They hypothesize that (1) neuroleptic-

1 Address for correspondence: Dr S. M. Stahl, Neuroscience Research Centre, Merck Sharp \& Dohme Research Laboratories, Terlings Park, Harlow, Essex CM20 2QR. 
Table 1. Tardive dyskinesia variants

\begin{tabular}{lll}
\hline \multicolumn{1}{c}{ Variant } & \multicolumn{1}{c}{ Reference } \\
\hline $\begin{array}{l}\text { Tardive oro-buccal-lingual-masticatory } \\
\text { dyskinesia }\end{array}$ & $\begin{array}{l}\text { Marsden et al. (1975) } \\
\text { Stahl et al. (1982) } \\
\text { Stahl (1986) }\end{array}$ \\
Tardive limb dyskinesia & $\begin{array}{l}\text { Marsden } \text { et al. (1975) } \\
\text { Stahl et al. (1982) } \\
\text { Stahl (1986) }\end{array}$ \\
Tardive dystonia & Burke et al. (1982) \\
Tardive supersensitivity/rebound psychosis & Chouinard (1982) \\
& Chouinard et al. (1978) \\
Tardive Tourette syndrome & Stahl (1980) \\
& Klawans et al. (1978) \\
& Fog \& Pakkenberg (1980) \\
& DeVeaugh-Geiss (1980) \\
Tardive dysmentia/dysphrenia & Wilson et al. (1983) \\
& Forrest (1979) \\
Tardive akathisia & Barnes \& Braude (1985) \\
\hline \hline
\end{tabular}

induced acute akathisia progresses to (2) neuroleptic-induced chronic akathisia which, in turn, merges with (3) tardive akathisia, (or pseudo-akathisia), a harbinger of (4) tardive oro-buccallingual-masticatory or limb dyskinesia.

Such provocative concepts and radical thinking attempt to outline the natural history of a patient's response to neuroleptics starting with a longitudinal perspective of acute dosing and following it for several years. This approach is also supported by investigators who recognize that the natural history of tardive dyskinesia is very frequently superimposed upon the natural history of schizophrenia, the patients who most often receive neuroleptics. Thus, the sub-typing of chronic schizophrenia and the return to a Kraepelinian respect for the longitudinal course of the illness both play a role in contemporary thinking about the natural history of tardive dyskinesia.

At present, at least two points of view exist to explain the natural history of movement disorders in schizophrenic patients. Some investigators, notably Crow's group, have articulated Type I and Type II syndromes (Crow, 1981). According to this hypothesis some untreated chronic schizophrenic patients will begin an illness with positive symptoms (Type I), progress to predominantly negative symptoms (Type II) and possibly develop spontaneous movement disorders. However, most chronic schizophrenic patients will be taking chronic neuroleptic therapy. Will their movement disorders be attributable to a variant of tardive dyskinesia or to Type II schizophrenia?

Different investigators have hypothesized that the natural history of movement disorders following neuroleptic administration is largely superimposed upon the natural history of schizophrenia. Thus, Barnes \& Braude (1985) have considered the natural history of chronic schizophrenia in their formulation of the natural history of akathisia evolving into tardive dyskinesia. They have suggested that acute akathisia in a patient with positive symptoms of schizophrenia may progress to pseudo-akathisia in a chronic schizophrenic patient with negative symptoms. Accordingly, acute neuroleptic administration to a younger patient with positive symptoms may be manifested as subjective restlessness (acute akathisia). Ultimately, at the end of twenty years of neuroleptic exposure superimposed upon twenty years of chronic schizophrenia, the clinician may be left with a patient who has predominantly negative symptoms of schizophrenia plus any one of a number of tardive dyskinesia variants (Table 1). Careful prospective studies of chronic neuroleptic treatment in chronic schizophrenia are currently being generated and will be invaluable in gaining an understanding of the natural history of neuroleptic-induced movement disorders, as opposed to movement disorders associated with schizophrenia itself (Stahl, 1985). 


\section{TREATMENT}

This subject has been adequately reviewed elsewhere (DeVeaugh-Geiss, 1982; Jeste \& Wyatt, 1979), and will not be emphasized here. Suffice it to say, treatment is bitterly disappointing. Neurotransmitter imbalance hypotheses based upon dopaminergic excess, acetylcholine deficiency and GABA deficiency have played the major role in attempts to correct tardive dyskinesia (Stahl, 1985, 1986). Currently, pharmacological efforts to decrease dopamine excess are themselves associated with tardive dyskinesia (Stahl, 1986; DeVeaugh-Geiss, 1982; Jeste \& Wyatt, 1979), and pharmacological treatments to enhance cholinergic (Stahl et al. 1982) or GABA-ergic (Stahl et al. 1985) tone are poorly efficacious at best. Although neuroleptic withdrawal might be the best treatment for a patient who has no need for neuroleptics, the clinician is often faced with treating a patient whose psychosis is more malignant than his movement disorder. Thus, many patients, by necessity, have neuroleptic medications continued in order to control psychosis, while exacerbating the ultimate severity of their tardive dyskinesia.

Although the future may bring pharmacological treatments which can counteract the consequences of chronic neuroleptic treatment, such a temporary measure will not ultimately be satisfactory. The next breakthrough in the treatment of tardive dyskinesia must be the development of a pharmacological treatment for psychosis which does not cause tardive dyskinesia.

\section{PREVENTION}

Until the pharmacology of psychosis can be controlled with new chemical entities which do not produce tardive dyskinesia, the only prevention for a practising clinician today is to use appropriately those neuroleptics which are available. This means matching the risk of treatment with the risk of the mental disorder. Thus, conservative use of neuroleptics is the hallmark of tardive dyskinesia prevention today (Barnes \& Braude, 1985; DeVeaugh-Geiss, 1982; Jeste \& Wyatt, 1979).

New hope arises from at least two areas of contemporary research for the discovery of 'non-neuroleptic' neuroleptics. That is, new drugs are being sought which can alleviate psychosis without causing extrapyramidal side-effects, possibly by blocking dopamine- 2 receptors in mesolimbic dopamine pathways as opposed to nigrostriatal dopamine pathways (Ferris et al. 1984; Davidson et al. 1983; Jalfre et al. 1983). Early leads from second generation anti-psychotic drugs such as BW234U (Ferris et al. 1984), piquindone (RO22-1319) (Davidson et al. 1983), and the substituted benzamides (Jalfre et al. 1983), have increased hopes that control of psychotic symptoms may someday be accomplished with much less risk of akathisia, Parkinsonism (and, possibly, tardive dyskinesia) than exists for the currently marketed neuroleptics. However, pharmacological interventions aimed at receptors other than dopamine receptors may ultimately be necessary. Thus, the discovery that neuropeptides are co-released in dopamine pathways thought to be responsible for mediating psychosis generate provocative leads for the potential discovery of a new antipsychotic agent (Iversen, 1983; Lundberg \& Hokfelt, 1983). The most promising peptide receptors to consider are those co-localized in dopamine pathways - i.e. neurotensin (Nemeroff \& Cain, 1985) and cholecystokinin (Snyder, 1980).

Contemporary thinking about the chemical nature of neurotransmission has evolved today such that neurons are conceptualized as releasing not one, but possibly two neurotransmitters (Iversen, 1983, 1986; Lundberg \& Hokfelt, 1983; Hokfelt et al. 1986). These neurotransmitters are often paired so that a classical neurotransmitter, like dopamine, is coupled with a neuromodulator in the peptide series, like neurotensin or cholecystokinin. Furthermore, neurotransmitters may act at synapses which are distant from the synapse where they are released (Iversen, 1986). These observations give rise to the hope that a new drug capable of modulating neurotensin or cholecystokinin receptors could have anti-psychotic properties without causing acute akathisia, or acute Parkinsonism. If natural history studies demonstrate that absence of acute side-effects predicts absence of chronic side-effects, then these new drugs could be potential anti-psychotic agents which do not cause tardive dyskinesia. 


\section{REFERENCES}

Barnes, T. R E. \& Braude, W. M. (1985). Akathisia variants and tardive dyskinesia. Archives of General Psychiatry 42, 874-878.

Burke, R. E., Fahn, S., Jankovec, J., Marsden, C. D., Lang, A. E., Gollomp, S. \& Ilson, J. (1982). Tardive dystonia: late onset and persistent dystonia caused by antipsychotic drugs. Neurology 32, $1335-1346$.

Chouinard, G. (1982). Neuroleptıc-induced supersensitivity psychosis. In Tardive Dyskinesia and Related Involuntary Movement Disorders (ed. J. DeVeaugh-Geiss), pp. 109-115. John Wright: Boston.

Chouinard, G., Jones, B. D.\& Annable, L. (1978) Neuroleptic-induced supersensitivity psychosis. American Journal of Psychlatry 135, $1409-1410$

Crow, T. J (1981). Positive and negatıve schizophrenia symptoms and the role of dopamine. British Journal of Psychiatry 139, 251-254.

Davidson, A. B., Boff, I., MacNeil, D. A. \& Cook, L. (1983). Pharmacological effects of RO22-1319: a new antipsychotic agent. Psychopharmacology 79, 32-39.

DeVeaugh-Geiss, J. (1980). Tardive Tourette syndrome. Neurology 30, 562-563.

DeVeaugh-Geiss, J. (ed.) (1982). Tardive Dyskinesia and Related Involuntary Movement Disorders. John Wright' Boston.

Ferris, R., Cooper, B., Harfenist, M. \& Maxwell, R. (1984). The pharmacology of new non-dopamine blocking antipsychotic, BW234U. Clinical Neuropharmacology 7, 146-147.

Fog, R \& Pakkenberg, H. (1980) Theoretical and clinical aspects of Tourette Syndrome (chronic multiple tics). Journal of Neural Transmission (Suppl.) 16, 211-215.

Forrest, D. V. (1979). Tardive dysphrenia and subjective akathısia. Journal of Clinical Psychiatry 40, 87.

Hokfelt, T., Fuxe, K. \& Pernow, B. (eds.) (1986) Coexistence of Neuronal Messengers. A New Principle in Chemical Transmission. Progress in Brain Research. Elsevier: Amsterdam (n the press).

Iversen, L. L. (1983). Neuropeptıdes - what next? Trends in Neurosciences 6, 293-294.

iversen, L. L. (1986). Chemicals signalling in the nervous system. In Coexistence of Neuronal Messengers A New Principle in Chemical Transmission (ed. T. Hokfelt, K. Fuxe and B. Pernow). Progress in Brain Research. Elsevier: Amsterdam (in the press).
Jalfre, M., Bucher, B., Dorme, N., Mocquet, G. \& Porsolt, R. D. (1983). Neuropharmacological profile of MD 790501, a new benzamide derivative. Archives Internationales de Pharmacodynamie et de Therapie 264, 232-256.

Jeste, D. V. \& Wyatt, R. P. (1979). In search of treatment for tardive dyskinesia: review of the literature. Schizophrenta Bulletin 5, 251-293.

Klawans, H. L., Falk, D. K., Nausieda, P. A. \& Weiner, W. J. (1978). Gilles de la Tourette Syndrome after long-term chlorpromazine therapy. Neurology 28, 1064-1066.

Lundberg, J. M. \& Hokfelt, T. (1983). Coexistence of peptides and classical neurotransmitters. Trends in Neurosciences 6, 325-333.

Marsden, C. D., Tarsy, D. \& Baldessarini, R. J (1975). Spontaneous and drug-induced movement disorders in psychotic patients. In Psychiatric Aspects of Neurological Disease (ed. D. F. Benson and D. Blumer), pp. 219-265. Grune and Stratton: New York.

Nemeroff, C. B. \& Cain, S. T. (1985). Neurotensin-dopamine interactions in the CNS. Trends in Pharmacological Sciences 4, 201-205.

Snyder, S. H. (1980). Brain peptides as neurotransmitters. Sctence 209, 976-983.

Stahl, S. M. (1980). Tardive Tourette syndrome in an autistic patient after long-term neuroleptic administration. American Journal of Psychiatry 137, 1267-1269

Stahl, S. M. (1985). Akathisia and tardive dyskinesia: changing concepts. Archives of General Psychiatry 42, 915-917.

Stahl, S. M. (1986). Neuropharmacology of movement disorders: comparison of drug-induced and spontaneous movement disorders. In Movement Disorders (ed. N. S. Shah and A. G. Donald). Plenum: New York (in the press).

Stahl, S. M., Davis, K. L. \& Berger,P. A. (1982). Neuropharmacology of tardive dyskinesia, spontaneous dyskinesia, and other dystonias. Journal of Clincal Psychopharmacology 2, 321-328.

Stahl, S. M., Thornton, J. E., Simpson, M. L., Berger, P. A. \& Napoliello, M. J. (1985). GAMMA-Vinyl-GABA treatment of tardive dyskinesia and other movement disorders. Biological Psychiatry 20, 888-893.

Wilson, I. C., Garbutt, J. C., Lanier, C. F., Moylan, J., Nelson, W. \& Prange, A. J. (1983). Is there a tardive dysmentia? Schizophrenia Bulletin 9, 187-192 